Indian J Anim Health (2021), 60(2): 295-297

DOI: https://doi.org/10.36062/ijah.2021.07021

\title{
Surgical correction of traumatic proptosis in a heifer: A case report
}

\author{
M. Sharma ${ }^{*}$, B. Sarma ${ }^{2}$, K. Saikia ${ }^{3}$ and B. K. Sarma ${ }^{1}$ \\ ${ }^{1}$ Department of Surgery and Radiology, Lakhimpur College of Veterinary Science, Assam Agricultural \\ University, Joyhing, North Lakhimpur- 787 051, Assam, India; ${ }^{2}$ Department of Surgery and \\ Radiology, College of Veterinary Science, Assam Agricultural University, Khanapara, Guwahati- \\ 781 022, Assam, India ; ${ }^{3}$ Department of Animal Nutrition, College of Veterinary Science, Assam \\ Agricultural University, Khanapara, Guwahati-781 022, Assam, India
}

\begin{abstract}
An indigenous heifer (Lakhimi breed) was presented to Veterinary Clinical Complex with a history of a recent automobile accident, causing injury to the right eyeball. Clinical examination revealed protrusion of the right eyeball with swelling and intense red discolouration of the exposed sclera. Immediate surgical intervention with lateral canthotomy to place the eyeball into the socket and tarsorrhaphy to retain the eyeball in place, along with subsequent supportive therapy maintained the normal vision of the animal.
\end{abstract}

Key words: Bovine, Canthotomy, Eyeball, Proptosis, Tarsorrhaphy

Proptosis refers to the protrusion of the eyeball beyond its orbital rim and eyelids, resulting in entrapment of the dorsal and ventral eyelids posterior to the globe (Kumar et al., 2016; Pe'er et al., 2020). Proptosis is not frequently encountered in cattle because of having complete orbital rim, but it may occur from severe blunt trauma to the head region near orbit, fracture of orbital bones or due to some disease conditions (Mosbah, 2008). Haemorrhage into the orbit and engorgement of the vessels leading to swelling of the eyeball combined with muscular spasm of the eyelid makes it difficult to reposition the proptosed eyeball into its original position (Parmar et al., 2016). Recovery generally depends on the presence of pupillary light reflex, duration of trauma to treatment, the severity of damage or viability of injured ocular and extra ocular tissues along with other systemic trauma (Kumar et al., 2016; Parmar et al., 2016; Ali and Mostafa, 2019). However, early intervention is essential to maintain vision by preventing further desiccation and damage to the cornea and inner part of the eyeball. The present communication reports the successful surgical management with the restoration of vision in a case of traumatic proptosis in cattle from Assam, India.

A heifer (7 months) was presented to Veterinary Clinical Complex, with a history of recent automobile accident 3 to 4 hours ago. Clinical evaluation revealed protrusion of right eyeball with periorbital haemorrhage and engorgement of vessels resulting in the periorbital swelling, without any orbital rim fracture, which was confirmed by digital or physical palpation and based on the absence of signs like swelling or redness surrounding the area. The eyeball protruded beyond the lid margins which resulted inability of the lid to close properly over the proptosed eyeball with visible corneal desiccation (Fig. 1.a). The pupillary light reflex and corneal reflex were evaluated by pointing torchlight into the eye directly and touching the cornea with a sterile cotton bud respectively. Again, the response of the eye against physical movement of author's hand was also observed. Based on all these three tests and looking apparently healthy cornea, the animal was confirmed to have an intact vision. The case was diagnosed as

*Corresponding Author, E mail: manavs46@aau.ac.in 
unilateral proptosis and immediate surgical intervention was planned. Further clinical examination revealed that all other vital parameters like body temperature, respiration rate were within the normal range, except mild increase in heart rate and pulse rate $(83$ per minute and 77 per minute respectively).

The heifer was restrained manually. The proposed eye was thoroughly irrigated with sterile normal saline solution to remove all dirt and debris, and lubricated with antiseptic eye ointment immediately to prevent further desiccation. A clean ice pack was applied on the periorbital area for two minutes to control minor bleeding. Local analgesia was achieved through retro-bulbar nerve block using $2 \%$ lignocaine hydrochloride, along with local infiltration in the bulbar conjunctiva. Lateral canthotomy was performed, and the eyeball was replaced in orbit, followed by canthorrhaphy (Fig. 1.b) and temporary tarsorrhaphy (Fig. 1.c) with simple interrupted and simple horizontal mattress sutures respectively, using No.1 black braided silk. Prior to tarsorrhaphy, a mixture of $0.5 \mathrm{~mL}$ prednisolone acetate $(1 \%)$ and $0.5 \mathrm{~mL}$ gentamicin (4\%) was administered subconjunctively using an insulin syringe. Postoperatively, ceftriaxone @ $10 \mathrm{mg} / \mathrm{kg}$ was injected intravenously, daily for 7 days, and flurbiprofen eye drop was instilled thrice daily for 10 days. On the $10^{\text {th }}$ postoperative day, the sutures were removed, and complete recovery with clear vision could be noticed which was assessed as mentioned earlier (Fig. 1.d).

Proptosis of the eyeball is very common in dogs and cats because of their incomplete orbital rim. In these species, the orbital ligament cannot withstand the traumatic insult, resulting in protrusion of the eyeball. Proptosis due to automobile injury has been reported in dogs and cats (Kumar et al., 2016; Ali and Mostafa, 2019). Proposes of eye in dogs following infighting was also reported by Sarma and Nath (1999). Though traumatic proptosis is rare in ruminants because of the complete orbital rim, it has been reported by some authors (Mosbah, 2008; Mahesh et al., 2016). In the current communication, the swollen eyeball could be repositioned into the orbital socket only after canthotomy and was retained by using canthoplasty and tarsorrhaphy. Local infiltration around the eyelids along with retrobulber nerve block with $2 \%$ lignocaine hydrochloride gave suitable conditions for the surgical procedure.

Engorgement of the vessels disappeared following replacing the eyeball in the orbit because of the release of extra pressure. The injured heifer was an indigenous breed and was not managed in a scientific way, leading to malnourishment. This might have led to the loosening of supporting connective tissue of the eyeball. Based on this, it was hypothesized that loose connective tissue might have a secondary influence on the occurrence of the present case. Lee (1949) also reported that connective tissue might lose its strength following malnutrition. On the other hand, tearing of supporting structures due to trauma might have also contributed to the condition. The success of treatment depends on the viability of the ocular and extra ocular tissues, degree of injury to the eyeball and duration from occurrence to treatment (Kumar et al., 2016; Parmar et al., 2016; Ali and Mostafa 2019). In the present case, complete recovery with functional vision could be achieved due to early presentation of the case within 4 hours of occurrence. Moreover, use of prednisolone and flurbiprofen might have further reduced the inflammation and oedema. Use of steroids in traumatic proptosis has also been reported (Kumar et al., 2016; Parmar et al., 2016). Tarsorrhaphy helped to retain the eyeball in socket.

From this report, it can be concluded that immediate medical attention is vital for restoring vision of a proptosed eye and level of viability of injured ocular and periocular tissues, play an important role in the prognosis.

Conflict of interest: Authors have no conflict of interest in this study. 
Indian Journal of Animal Health, December, 2021

Surgical correction of traumatic proptosis

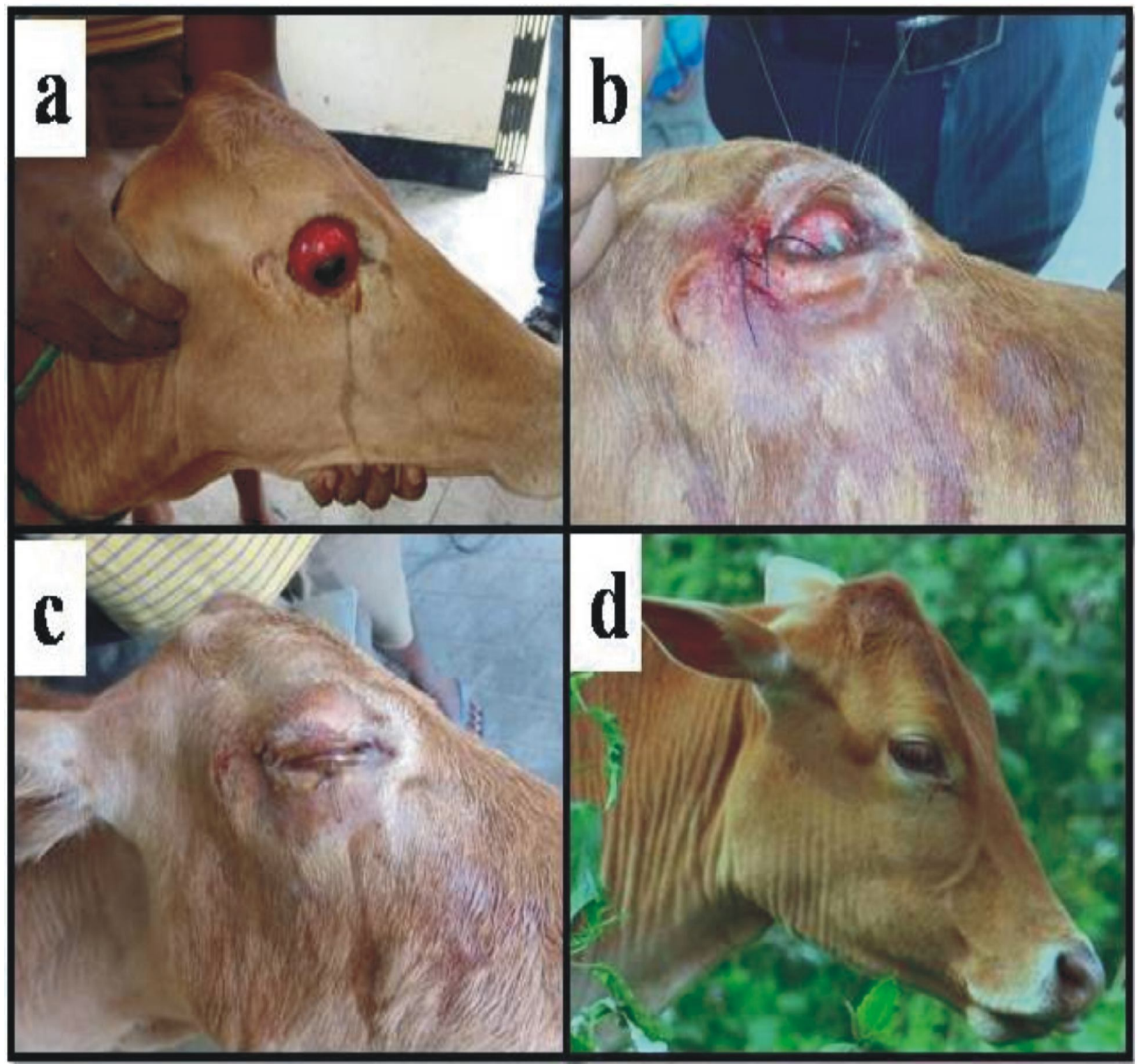

Fig. 1. Figure represents surgical correction; a) proptosed eyeball with visible corneal desiccation, b) canthorrhaphy on the lateral canthus, c) tarsorrhaphy to secure the protruded eyeball, d) the animal after 6 months 


\section{REFERENCE}

Ali KM and Mostafa AA, 2019. Clinical findings of traumatic proptosis in small-breed dogs and complications associated with globe replacement surgery. Open Vet J, 9(3): 222-229, doi: 10.4314/ ovj.v9i3.6

Kumar A, Rohi RR, Pawar P and Kumar P, 2016. Management of traumatic ocular proptosis in cat. Int J Sci Environ Technol, 5(3): 1163-1166

Lee R, 1949. The direct effect of malnutrition on tissue degeneration. Address to the American Academy of Applied Nutrition Seattle, Washington Chapter, November 17, 1949. Available in https:// www.seleneriverpress.com/images/pdfs/885_ THE_DIRECT_EFFECT_OF_MALNUTRITION_ ON_TISSUE_DEGENERATION_1949.pdf $\left(1^{\text {st }}\right.$ July, 2021)
Mahesh R, Sivasudharshan L, Sumiran N, Kamalakar G and Rambabu K, 2016. Surgical management of traumatic proptosis in a kid. Int J Sci Environ Technol, 5(6): 4163-4166

Mosbah E, 2008. Surgical management of some ocular affections in domestic animals. SCVMJ, XIII (2): 601-623

Parmar JJ, Mahla JK and Parikh PV, 2016. Surgical management of proptosis in a dog. Intas Polivet, 17(2): 374-375

Pe'er O, Oron L and Ofri R, 2020. Prognostic indicators and outcome in dogs undergoing temporary tarsorrhaphy following traumatic proptosis. Vet Ophthalmol, 23(2): 245-251, doi: 10.1111/vop.12713

Sarma B and Nath S, 1999. Proptosis of an eye in a dog - case report. Intas Polivet, II (2): 183-184

Received 24.06.21, Accepted - 09.08.2021, Published-04.09.2021 (Online), 01.12.2021 (Print) Section Editor: Prof. S. K. Nandi, Associate Editor 